\title{
Isigny-sur-Mer - Les Coudriaux
}

$\mathrm{n}^{\circ} 3455$

\section{François Coupard}

\section{(2) OpenEdition}

\section{Journals}

Édition électronique

URL : http://journals.openedition.org/adlfi/16962

ISSN : 2114-0502

Éditeur

Ministère de la culture

\section{Référence électronique}

François Coupard, "Isigny-sur-Mer - Les Coudriaux», ADLFI. Archéologie de la France - Informations [En ligne], Basse-Normandie, mis en ligne le 16 mars 2016, consulté le 01 mai 2019. URL : http:// journals.openedition.org/adlfi/16962

Ce document a été généré automatiquement le 1 mai 2019.

(C) Ministère de la Culture et de la Communication, CNRS 


\title{
Isigny-sur-Mer - Les Coudriaux
}

$n^{\circ} 3455$

\author{
François Coupard
}

Lien Atlas (MCC) :

http://atlas.patrimoines.culture.fr/atlas/trunk/index.php?

ap_theme=DOM_2.01.02\&ap_bbox=-1.141;49.284;-1.057;49.327

1 L'opération de diagnostic conduite sur la commune d'Isigny-sur-Mer s'inscrit dans le cadre d'un projet de lotissement et d'extension de la zone d'activités. Elle se situe le long de la RN 13. Le contexte archéologique est très largement documenté par des opérations de diagnostic et de fouille situées à proximité. Ces diverses opérations ont permis de mettre au jour des vestiges dont les datations sont comprises entre le Bronze final/ premier âge du Fer et l'époque moderne, mais ce sont principalement les périodes laténienne et gallo-romaine qui sont les mieux illustrées. Les principaux résultats des investigations archéologiques menées à Isigny permettent de saisir une évolution des formes d'habitat entre La Tène finale et le Bas-Empire. L'occupation protohistorique est représentée par deux enclos dont les surfaces sont inférieures à $2000 \mathrm{~m}^{2}$ ainsi que des crémations associées. L'abandon de ces enclos marque le début de l'implantation d'une importante villa antique dont la surface est estimée supérieure à $2500 \mathrm{~m}^{2}$. Aucune trace de réoccupation médiévale des ruines antiques n'a été observée, le haut Moyen Âge n'étant à ce jour illustré que par les vestiges monumentaux localisés au centre de la commune. Les rares indices disponibles nous montrent cependant que la villa du Tuilley a laissé la place, entre le Moyen Âge central et l'époque moderne, à des surfaces agricoles localisées en périphérie du bourg d'Isigny.

2 Le présent diagnostic couvre une superficie de $97000 \mathrm{~m}^{2}$. Le terrain sondé à près de $12 \%$ a livré quelques vestiges dont les attributions semblent couvrir la fin de l'âge du Bronze et le début de l'âge du Fer. L'occupation la plus ancienne se résume à la découverte d'une structure tumulaire circulaire (quelques tessons semblent attribuables à la transition Bronze moyen/final) de 9 mètres de diamètre abritant deux structures en creux. La seconde occupation dont l'attribution chronologique semble assurée tient dans la découverte d'une fosse livrant un mobilier céramique caractéristique du premier âge du 
Fer (Hallstatt C ?). Un réseau fossoyé possiblement en lien avec cette fosse (contact stratigraphique) semble se développer selon un axe nord-sud. Un à plusieurs fossés de refend sont susceptibles de diviser en lopins cette trame parcellaire. Le diagnostic a permis la découverte de nombreux fossés, qui livrent dans l'ensemble très peu de mobilier. Malgré tout, les quelques vestiges céramiques issus de ces fossés semblent de facture protohistorique. Ces découvertes apportent de nouveaux éléments, notamment sur l'emprise agraire possible des établissements enclos protohistoriques détectés au nord-ouest de la zone de diagnostic. Ces données placeraient l'origine des occupations au premier âge du Fer.

3 L'opération a également livré quelques fossés correspondant à la trame parcellaire moderne, voire contemporaine. Elle a pu être datée par la découverte de céramiques de type « grès du Bessin ".

INDEX

Index géographique : Basse-Normandie, Calvados (14), Isigny-sur-Mer (14342)

operation Diagnostic (EV)

Mots-clés : tumulus fossé, fosse, céramique

\section{AUTEURS}

FRANÇOIS COUPARD

Inrap 